\title{
EFECTOS SOBRE PARÁMETROS BIOQUÍMICOS Y BIOLÓGICOS BACTERIANOS EN SUELOS QUE CONTIENEN CONCENTRACIONES PERMISIBLES DE METALES
}

\author{
Arnaldo José ARMADO-MATUTE ${ }^{1 *}$, Jesús Alberto PÉREZ-GUERRERO ${ }^{1}$, Diana DURÁN², \\ Doris REYES ${ }^{3}$, María Elena MEDINA ${ }^{2}$ y Óscar Enrique VALBUENA-VÍLCHEZ ${ }^{3}$
}

${ }^{1}$ Centro de Investigación y Extensión en Ambiente, Biología y Química (AMBIOQUIM), Departamento de Química, Facultad Experimental de Ciencias y Tecnología, Universidad de Carabobo, Av. Salvador Allende, Bárbula, Estado Carabobo, Venezuela, C.P. 2005

${ }^{2}$ Departamento de Química, Facultad Experimental de Ciencias y Tecnología, Universidad de Carabobo. Avenida Salvador Allende, Bárbula, Estado Carabobo, Venezuela, C.P. 2005

${ }^{3}$ Centro de Biotecnología Aplicada, Departamento de Biología, Facultad Experimental de Ciencias y Tecnología, Universidad de Carabobo, Bárbula, Estado Carabobo, Venezuela, C.P. 2005

*Autor para correspondencia: armadoa@uc.edu.ve

(Recibido abril 2017; aceptado octubre 2017)

Palabras clave: diversidad bacteriana, carga bacteriana, contaminación con metales, normativas ambientales

\section{RESUMEN}

La contaminación de ambientes naturales por metales es básicamente producto de actividades antrópicas, tales como siderurgia, minería, galvanoplastia y Curtiembre es el lugar donde ocurre el proceso de curtido de pieles, no el proceso en sí de pieles y cuero. Como consecuencia, los microorganismos en los ambientes impactados se someten a condiciones estresantes, provocando una disminución de la biomasa y diversidad biológica, particularmente la bacteriana. En este estudio se reportan disminuciones estadísticamente significativas en el contenido de carbono orgánico total $(70 \%)$, actividad ureásica (54\%), biomasa bacteriana (47\%) y carga bacteriana (30-80\%) en suelos que contienen metales en niveles considerados permisibles por la legislación venezolana. El cociente respiración basal/biomasa microbiana se incrementó en $58 \%$ respecto al suelo testigo. La diversidad bacteriana se redujo y se lograron aislar sólo 12 morfotipos en placas de agar LB suplementadas con sales de $\mathrm{Cr}^{3+}, \mathrm{Cr}^{6+}, \mathrm{Ni}^{2+}, \mathrm{Pb}^{2+}, \mathrm{Zn}^{2+}, \mathrm{Fe}^{2+} \mathrm{y}$ $\mathrm{Co}^{2+}$. Cinco de estos morfotipos fueron asignados a los géneros bacterianos Rothia, Vibrio, Klebsiella, Acinetobacter y Raoultella. El pH (9) y la concentración de metales $\left(\mathrm{Cr}^{3+}, \mathrm{Cr}^{6+} \mathrm{y} \mathrm{Ni}^{2+}\right)$ fueron parámetros determinantes en la reducción de la diversidad y carga bacterianas. Los datos reportados deberían constituir un llamado de alerta a la autoridad ambiental venezolana para revisar y establecer los niveles permisibles de metales en ambientes naturales, de tal manera de que los parámetros bioquímicos y fisiológicos del suelo no se afecten negativamente; adicionalmente, la carga y diversidad microbianas deberían ser incluidas como bioindicadores de salud para suelos.

Key words: bacterial diversity, bacterial load, contamination by metals, environmental normative

\begin{abstract}
Contamination of natural environments by metals is basically due to anthropogenic activities such as iron and steel industries, mining, electroplating and tannery. As a
\end{abstract}


consequence, proliferating microbes in such environments are subjected to stress conditions which induce decreases of the microbial diversity and biomass, particularly the bacterial one. This study reports statistical significant reductions of the total organic carbon content $(70 \%)$, urease activity $(54 \%)$, microbial biomass $(47 \%)$, and bacterial load $(3080 \%)$ in soil samples containing permissible levels of metals according to the Venezuelan legislation. Besides, the basal respiration/microbial biomass ratio increased $58 \%$ respect to the witness soil. The bacterial diversity was severally reduced and only 12 bacterial morphotypes were isolated from agar LB plates supplemented with $\mathrm{Cr}^{3+}$, $\mathrm{Cr}^{6+}, \mathrm{Ni}^{2+}, \mathrm{Pb}^{2+}, \mathrm{Zn}^{2+}, \mathrm{Fe}^{2+}$, and $\mathrm{Co}^{2+}$ salts. Five of these strains were assigned to Rothia, Vibrio, Klebsiella, Acinetobacter and Raoultella bacterial genera. The $\mathrm{pH}(9)$ and metal concentrations $\left(\mathrm{Cr}^{3+}, \mathrm{Cr}^{6+}\right.$ and $\left.\mathrm{Ni}^{2+}\right)$ were the most important parameters involved in reducing the bacterial diversity and load. The reported data should constitute an alarm call to the Venezuelan environmental authority to revise and set the metal permissible levels in natural environments, in such a way the soil biochemical and physiological parameters are not negatively affected; besides, microbial load and diversity should be included as health bioindicators to soils.

\section{INTRODUCCIÓN}

El suelo es uno de ambientes naturales donde proliferan los microorganismos, particularmente las bacterias, que constituyen comunidades extremadamente complejas de elevada diversidad biológica. Las bacterias de una misma especie conforman poblaciones y la interacción de poblaciones de diferentes especies provoca un equilibrio que asegura una relativa constancia de la microbiota (Black 2012).

La interacción de elementos abióticos y la microbiota mantiene las características deseables de los suelos para sustentar labores agrícolas, agropecuarias y muchas otras (Gadd 2010).

Mediante diferentes actividades antrópicas, se descargan usualmente elevadas cantidades de sustancias perjudiciales en los suelos que no pueden ser degradadas o modificadas en tiempos adecuados por la población microbiana, alterando el equilibrio natural de la microbiota. En consecuencia, ocurre una acumulación de dichas sustancias en los suelos, las cuales contaminan el medio ambiente y ejercen efectos negativos sobre las poblaciones microbianas. Esto ocasiona la disminución masiva de muchas poblaciones bacterianas, de las cuales sobrevive un número reducido, o bien elimina una gran proporción de las especies de estas comunidades. Así los suelos contaminados presentan muy baja diversidad biológica y reducida biomasa bacteriana (Smets et al. 2003, Piotrowska-Seget et al. 2005, Silver y Phung 2005, Bozo et al. 2007, Dell'Amico et al. 2008).
Adicionalmente, estas condiciones de estrés provocan cambios fisiológicos en las bacterias que impiden su proliferación (McDougald et al. 1998, Couter 2003, Darcan et al. 2009, Cortez et al. 2013).

Los metales, cuya escoria es generada por actividades siderúrgicas, galvanización, minería, curtiembre de pieles y cueros, entre otras, al ser descargados y superar niveles críticos contaminan los ambientes naturales, fundamentalmente suelos y aguas, modificando la microbiota - incluyendo la bacteriana-, lo cual a posteriori modifica negativamente las características químicas y fisicoquímicas de los ecosistemas (Torsvik y Ǿvreas 2002).

En este trabajo se determinan parámetros bioquímicos (contenido de materia orgánica total, actividad ureásica, respiración basal y biomasa microbiana) y biológicos (carga y diversidad bacteriana) en muestras de suelos con bajas concentraciones de metales, consideradas permisibles según las normas para el control de la recuperación de materiales peligrosos y el manejo de los desechos peligrosos de la legislación venezolana vigente (Decreto 2635, Gaceta Oficial 1998)

Adicionalmente, se identifican a nivel de género algunas de las cepas bacterianas aisladas del suelo impactado, se determina la resistencia y las concentraciones mínimas inhibitorias para níquel y cromo trivalente y hexavalente.

Con los resultados obtenidos en este trabajo, se pretende dar una voz de alerta a los entes encargados de generar normativas ambientales en Venezuela, de tal manera que se puedan proponer cambios adecuados que eviten la modificación de la microbiota del suelo en cuanto a su diversidad y cantidad. 


\section{MATERIALES Y MÉTODOS}

\section{Recolección de muestras de suelo}

Las muestras de suelo impactado con metales se colectadaron en terrenos pertenecientes a una empresa dedicada a la actividad metalúrgica, ubicada en Tinaqui1lo, Estado Cojedes, Venezuela $\left(9^{\circ} 55^{\prime} 26.958^{\prime \prime} \mathrm{N}, 68^{\circ}\right.$ 17 '4.405" O), la cual suspendió su actividad productiva en 2002. Se realizaron dos muestreos en la parcela de terreno donde se descargaba la escoria metálica, la cual no fue sometida a remediación: el primero en época de sequía (enero) y otro en época de lluvia (mayo).

Para tal efecto se seleccionó una parcela de terreno de $36000 \mathrm{~m}^{2}(240 \times 150 \mathrm{~m})$ adyacente a la planta de producción, en la cual se desechaba la escoria y residuos minerales provenientes del proceso de fabricación. La parcela se dividió en tres sectores de $12000 \mathrm{~m}^{2}(80 \times 150 \mathrm{~m})$ : el sector 1 ubicado en la zona más cercana a la planta, desde 0 hasta $80 \mathrm{~m}$; el sector 2 desde 80 hasta $160 \mathrm{~m}$, y el sector 3 desde 160 hasta $240 \mathrm{~m}$. Cada sector se dividió en tres subsectores de $4000 \mathrm{~m}^{2}(50 \times 80 \mathrm{~m})$.

Por cada subsección se recolectaron 10 muestras simples en un área de $10 \mathrm{~cm}^{2}$ y $20 \mathrm{~cm}$ de profundidad, en bolsas plásticas estériles. Las muestras simples se mezclaron formando muestras compuestas. El traslado al laboratorio se realizó en cavas refrigeradas a $4{ }^{\circ} \mathrm{C}$.

Las muestras se homogeneizaron y molieron; posteriormente se dividieron en dos porciones: una para las determinaciones biológicas y otra para las determinaciones de carbono orgánico total. La primera porción, sin secar, se tamizó en una malla $\left(2 \mathrm{~mm}^{2}\right)$ y se almacenó en nevera en recipientes cerrados herméticamente. La otra porción se secó al aire por $72 \mathrm{~h}$, luego se tamizó y se almacenó a temperatura ambiente en recipientes cerrados herméticamente.

A la par se colectaron 10 muestras simples en regiones del terreno donde no se depositaba material proveniente de la actividad productiva (muestra testigo), procesándose de acuerdo con lo anteriormente descrito. En total se dispuso de nueve muestras compuestas de suelo contaminado y una muestra testigo (por cada muestreo).

\section{Medios para el aislamiento y cultivo de cepas bacterianas autóctonas}

- Caldo nutritivo Luria Bertani (CLB): $10 \mathrm{~g}$ de triptona, $5 \mathrm{~g}$ extracto de lavadura y $10 \mathrm{~g}$ de $\mathrm{NaCl}$ por cada litro de medio de cultivo, ajustando el $\mathrm{pH}$ a 7.5 con $\mathrm{NaOH}$.

- Agar Luria Bertani (ALB): $10 \mathrm{~g}$ de triptona, $5 \mathrm{~g}$ extracto de lavadura y $5 \mathrm{~g}$ de $\mathrm{NaCl}, 12 \mathrm{~g}$ de agar-agar por cada litro de medio de cultivo, ajustando el $\mathrm{pH}$ a 7.5 con $\mathrm{NaOH}$.

- Agar restrictivo (AR): ALB al cual se le adicionaron 30 ppm de $\mathrm{Fe}(537 \mu \mathrm{M}), 20 \mathrm{ppm}$ de $\mathrm{Pb}(96 \mu \mathrm{M})$, $20 \mathrm{ppm}$ de $\mathrm{Zn}(305 \mu \mathrm{M}), 2.5 \mathrm{ppm}$ de $\mathrm{Cr}^{3+} \mathrm{y} \mathrm{Cr}^{6+}$ $(48 \mu \mathrm{M}), 2 \mathrm{ppm}$ de Ni $(34 \mu \mathrm{M})$ y $1 \mathrm{ppm}$ de Co $(17 \mu \mathrm{M})$. Se ajustó a pH 9.0 con $\mathrm{NaOH}$ y se esterilizó por 20 min a 15 psi de presión.

Los metales se añadieron a los medios restrictivos de cultivo como sales de calidad pro análisis: $\left(\mathrm{NH}_{4}\right)_{2} \mathrm{Fe}(\mathrm{SO} 4)_{2} .6 \mathrm{H}_{2} \mathrm{O}, \mathrm{Pb}\left(\mathrm{NO}_{3}\right)_{2}$, $\mathrm{ZnSO}_{4}, \mathrm{CrCl}_{3} .6 \mathrm{H}_{2} \mathrm{O}, \mathrm{K}_{2} \mathrm{Cr}_{2} \mathrm{O}_{7}, \mathrm{NiSO}_{4} .6 \mathrm{H}_{2} \mathrm{O}$ y $\mathrm{Co}\left(\mathrm{NO}_{3}\right)_{2} \cdot 6 \mathrm{H}_{2} \mathrm{O}$.

\section{Aislamiento y cultivo de cepas bacterianas au- tóctonas}

Alícuotas de las muestras compuestas de suelo (5g), recolectadas en la estación lluviosa (mayo), se dispersaron en $50 \mathrm{~mL}$ de CLB. Cada sistema se incubó a $33^{\circ} \mathrm{C}$ con agitación constante (140 rpm). Después de $24 \mathrm{~h}$ de incubación, los cultivos se filtraron en condiciones de esterilidad para eliminar partículas de suelo. De los filtrados se retiraron alícuotas para preparar diluciones seriadas, mismas que se sembraron a volúmenes de $100 \mu \mathrm{L}$ sobre AR y se incubaron a 33 ${ }^{\circ} \mathrm{C}$ durante $48 \mathrm{~h}$.

Las colonias aisladas con morfologías diferentes con base en su contorno, elevación, margen, tamaño y color, se recolectaron e inocularon en cuñas de AR y se almacenaron a $4{ }^{\circ} \mathrm{C}$ hasta su posterior identificación y uso.

\section{Análisis bioquímico de muestras de suelo}

Las muestras de suelo se procesaron y sometieron a determinaciones de porcentaje de carbono orgánico total (COT), respiración basal (RB), actividad ureásica (AU), biomasa microbiana $(\mathrm{BM})$ y carga bacteriana $(\mathrm{CB})$. De cada muestra se efectuaron tres réplicas, efectuándose 27 ensayos de muestras contaminadas y tres de la muestra testigo.

\section{Contenido de carbono orgánico total (COT)}

Se empleó el método de Wallinga et al. (1992), para lo cual se pesaron $0.5 \mathrm{~g}$ de suelo y se sometieron a oxidación vía húmeda con $\mathrm{K}_{2} \mathrm{CrO}_{4} \mathrm{y} \mathrm{H}_{2} \mathrm{SO}_{4}$ concentrado; tras $24 \mathrm{~h}$ en reposo se centrifugaron a $3000 \mathrm{rpm}$ y el sobrenadante se analizó mediante espectrofotometría a $660 \mathrm{~nm}$. La cuantificación se realizó por medio de una curva de calibración con sacarosa (0.1-0.4 mg C/mL), analizándose $1 \mathrm{~mL}$ del sobrenadante obtenido $(25 \mathrm{~mL})$. El contenido se expresó en g C/100 g de suelo seco. 


\section{Respiración basal (RB)}

Se siguió el método descrito por Anderson (1982), colocando $30 \mathrm{~g}$ de suelo en recipientes cerrados con un vial plástico con $15 \mathrm{~mL}$ de $\mathrm{NaOH} 0.1 \mathrm{M}$, para capturar el $\mathrm{CO}_{2}$ generado en oscuridad y a temperatura ambiente. $\mathrm{El} \mathrm{CO}_{2}$ se determinó por titulación con $\mathrm{HCl} 0.1 \mathrm{M}$, previa precipitación con $\mathrm{BaCl}_{2} 0.05 \mathrm{M}$. La tasa respiratoria se expresó en $\mathrm{mg} \mathrm{CO}_{2} / \mathrm{kg}$ de suelo $\times$ h calculados mediante la ecuación 1 .

$\mathrm{CO}_{2}(\mathrm{mg} / \mathrm{kg}$ suelo $\times \mathrm{h})=\frac{(a-b) \times C_{H C l} \times F C}{m s \times \mathrm{t}}$

Donde $a$ es el volumen de $\mathrm{HCl}$ gastado en el blanco $(\mathrm{mL}) ; b$ es el volumen de $\mathrm{HCl}$ gastado en la muestra $(\mathrm{mL}) ; \mathrm{CH}_{\mathrm{Cl}}$ es la concentración exacta de $\mathrm{HCl}(\mathrm{mol} / \mathrm{L})$; $F C$ incluye los factores de conversión estequiométricos y de unidades $(\mathrm{mg} \times \mathrm{g} \times \mathrm{L} / \mathrm{kg} \times \mathrm{mL} \times \mathrm{mol}) ; m s$ es la masa de suelo seco (g), y $t$ el tiempo (h).

\section{Actividad ureásica (AU)}

Se empleó el método de Kandeler y Gerber (1988), para lo cual se procesó $1 \mathrm{~g}$ de suelo con $0.5 \mathrm{~mL}$ de urea y se incubaron a $37^{\circ} \mathrm{C}$ durante $2 \mathrm{~h}$. Luego se adicionaron $10.0 \mathrm{~mL}$ de una solución de $\mathrm{KCl}-\mathrm{HCl}$, se agitaron todas las muestras por $30 \mathrm{~min}$ y se centrifugaron a $2500 \mathrm{rpm}$ por $10 \mathrm{~min}$.

Una alícuota de $1 \mathrm{~mL}$ (de un total de $11 \mathrm{~mL}$ ) se sometió a la determinación de amonio mediante reacción con una solución de salicilato/hidróxido y $2 \mathrm{~mL}$ de medio de oxidación, determinándose la absorbancia a $600 \mathrm{~nm}$. Se construyó una curva de calibración con contenido de 5-25 $\mu \mathrm{g}$ de $\mathrm{N}$ (amonio). La actividad se expresó en $\mu \mathrm{g} \mathrm{N} / \mathrm{g} \times \mathrm{h}$.

\section{Biomasa microbiana (BM)}

Se siguió el método de Anderson y Domsch (1978), se procesaron $30 \mathrm{~g}$ de suelo en presencia de $120 \mathrm{~g}$ de glucosa y un vial con $\mathrm{NaOH}$ 0.1 M. Después de $6 \mathrm{~h}$ de incubación en oscuridad, el $\mathrm{CO}_{2}$ producido se tituló con $\mathrm{HCl} 0.1 \mathrm{M}$ según lo establecido para la determinación de la respiración basal.

La BM se expresó en $\mathrm{mg} \mathrm{C} / 100 \mathrm{~g}$ con la relación $Y=40.04 X+0.37$, donde $Y$ es la BM y $X$ la respiración basal ( $\left.\mathrm{mL} \mathrm{CO}_{2} / 100 \mathrm{~g}\right)$. Para la conversión de la tasa respiratoria $\left(\mathrm{mg} \mathrm{CO}_{2}\right)$ a $\mathrm{mL}$ de $\mathrm{CO}_{2}$ se empleó el siguiente factor de conversión: $0.4908 \mathrm{mg} \mathrm{C}-\mathrm{CO}_{2}$ $=1.7995 \mathrm{mg} \mathrm{CO}=1 \mathrm{~mL} \mathrm{CO}_{2}$ a $25^{\circ} \mathrm{C}$.

\section{Carga bacteriana (CB)}

En $9 \mathrm{~mL}$ de $\mathrm{NaCl} 0.8 \%(\mathrm{p} / \mathrm{v})$ se suspendió $1 \mathrm{~g}$ de suelo, preparando diluciones seriadas $\left(10^{-2}, 10^{-3} \mathrm{y}\right.$ $10^{-4}$ ), de las cuales se sembraron por profundidad alícuotas de $0.1 \mathrm{~mL}$ en ALB suplementado con un $1 \mathrm{~g} / \mathrm{L}$ de antimicótico (fluconazol ${ }^{\circledR}$, Genven). Las placas se incubaron durante $24 \mathrm{~h}$ a $33^{\circ} \mathrm{C}$ y se determinaron las unidades formadoras de colonias (UFC/g) en un contador de colonias. Para estas determinaciones se tomaron muestras en las estaciones de lluvia (mayo) y sequía (enero).

\section{Identificación de los morfotipos bacterianos}

Para la identificación de los morfotipos bacterianos, las colonias aisladas de las muestras de suelo tomadas durante la estación lluviosa se sembraron en AR y se incubaron a $33{ }^{\circ} \mathrm{C}$ durante $24 \mathrm{~h} \mathrm{a} \mathrm{pH} \mathrm{9.0.} \mathrm{Su}$ pureza se evaluó al resembrarlas en el mismo medio y verificar la homogeneidad de sus características morfológicas.

La incubación se realizó a temperatura de $33{ }^{\circ} \mathrm{C}$ y $\mathrm{pH} 9.0$, porque estos valores fueron los que se determinaron en el medio ambiente y suelo donde se recolectaron las muestras.

Las pruebas de identificación realizadas fueron las siguientes: determinación de forma, tinción de Gram, esporas, prueba de oxidación/fermentación $(\mathrm{O} / \mathrm{F})$ de glucosa, lactosa, catalasa, motilidad, ácido sulfhídrico, indol, citrato, gas, nitratos, ureasa, lisina, almidón, rojo de metilo, agar con hierro de Kligler (KIA), prueba Voges-Proskauer, crecimiento en agar MacConkey, agar cetrimida, agar SalmonellaShigella (SS) y agar manitol salado.

Los procedimientos se detallan en Forbes et al. (2004) y Win et al. (2008). Las cepas se conservaron en cuñas de $\mathrm{AR}$, a $4{ }^{\circ} \mathrm{C}$ y se resembraron cada 60 días.

\section{Determinación de la sensibilidad a metales en las cepas bacterianas}

La sensibilidad de las cepas bacterianas, asignadas a géneros, se determinó por el método de difusión en placas AR (Abskharon et al. 2008), a pH 7.5 durante $18 \mathrm{~h}$ a $33^{\circ} \mathrm{C}$, aplicándose $20 \mu \mathrm{L}$ de las soluciones de metal $100 \mu \mathrm{M}$ por disco.

Los metales ensayados fueron $\mathrm{Co}^{2+}, \mathrm{Ni}^{2+}, \mathrm{Cr}^{3+}$, $\mathrm{Cr}^{6+} \mathrm{y} \mathrm{Na}^{+}$(este último incluido como control). Para preparar las placas AR, cada inóculo bacteriano se ajustó a una densidad óptica (DO) de 0.5 en la escala McFarland (Forbes et al. 2004). El diámetro de los halos de inhibición se determinó con una regla milimetrada.

Efectos de la concentración de metales y pH sobre el crecimiento bacteriano. Diseño experimental factorial $3^{3}$

Tres porciones de $200 \mathrm{~mL}$ de CLB se ajustaron a pH 6.0, 7.5 y 9.0; cada porción se dividió en tres 
volúmenes iguales, agregándose a cada uno la cantidad apropiada del metal para alcanzar concentraciones finales de 0.0, 5.0 y $10.0 \mathrm{mM}$. Los metales ensayados fueron $\mathrm{Ni}^{2+}, \mathrm{Cr}^{3+} \mathrm{y} \mathrm{Cr}^{6+}$. De esta manera, para cada metal se incubaron nueve sistemas, alcanzándose un total de 27 incubaciones.

A cada sistema se le adicionaron $100 \mu \mathrm{L}$ de la cepa bacteriana y se incubaron en reposo a $33^{\circ} \mathrm{C}$ durante siete días. Finalmente, se determinó la absorbancia a $540 \mathrm{~nm}$, la cual se corrigió mediante el respectivo sistema blanco (medio sin inóculo bacteriano).

Los datos obtenidos se sometieron a un análisis de varianza y se presentaron como gráficas de superficie de respuesta, relacionando la concentración del metal y el $\mathrm{pH}$ del medio con la variación de la densidad óptica (DO) del sistema (capacidad de duplicación de la población bacteriana).

\section{RESULTADOS Y DISCUSIÓN}

Los resultados correspondientes a los parámetros bioquímicos de las muestras de suelo impactado y testigo se detallan en el cuadro I.

El contenido de COT presentó valores muy bajos en los tres sectores impactados con metales, con un valor promedio de $0.436 \mathrm{~g} \mathrm{C} / 100 \mathrm{~g}$ de suelo seco (0.158 a $0.883 \mathrm{~g} \mathrm{C} / 100 \mathrm{~g})$. Al compararlo con el valor de la muestra testigo $(1.420 \mathrm{~g} \mathrm{C} / 100 \mathrm{~g}) \mathrm{se}$ estableció una reducción de $70 \%([1-0.436 / 1.420]$ $\times 100)$.
La AU también fue menor en los tres sectores estudiados, mostrando un valor promedio de $4.902 \mu \mathrm{g}$ $\mathrm{N} / \mathrm{g} \times \mathrm{h}(3.081$ a $6.032 \mu \mathrm{g} \mathrm{N} / \mathrm{g} \times \mathrm{h})$, mientras que el testigo se ubicó en $10.508 \mu \mathrm{g} \mathrm{N} / \mathrm{g} \times \mathrm{h}$; el descenso alcanzó $54 \%([1-4.902 / 10.508] \times 100)$.

La RB presentó promedios de 8.226 y $9.910 \mathrm{mg}$ $\mathrm{CO}_{2} / \mathrm{kg} \times \mathrm{h}$ para las muestras impactadas y testigo, respectivamente, con una disminución del $17 \%$ ([1 $-8.23 / 9.81] \times 100$ ), la cual no es estadísticamente significativa.

La BM mostró un promedio en las muestras impactadas de $12.087 \mathrm{mg} \mathrm{C} / 100 \mathrm{~g}(0.333$ a $28.481 \mathrm{mg} \mathrm{C} / 100 \mathrm{~g})$, $\mathrm{y}$ en el testigo de $22.789 \mathrm{mg} \mathrm{C} / 100 \mathrm{~g}$; la disminución se calculó en $47 \%([1-12.087 / 22.789] \times 100)$.

En conjunto estos resultados indicaron, de acuerdo con el análisis de varianza, disminuciones estadísticamente significativas para COT, AU y BM, y no significativas para RB. El COT y la AU son parámetros relacionados con los ciclos biogeoquímicos del $\mathrm{C}$ y N , elementos fundamentales para los procesos vitales en seres vivos.

La reducción en el COT implica carencia de moléculas orgánicas en el suelo impactado y la disminución de la AU indica una baja producción de $\mathrm{N}$ reducido (amonio). Ambos compuestos son utilizados por la microbiota como fuentes energéticas y moléculas precursoras para la síntesis de biomoléculas necesarias para la conformación de estructuras celulares, enzimas, coenzimas y funciones celulares típicas.

La reducción en la BM, que no puede incrementarse por falta de nutrientes, parece corroborar esta

CUADRO I. VARIACIÓN DE LOS PARÁMETROS BIOQUÍMICOS EN MUESTRAS DE SUELO IMPACTADOS Y NO IMPACTADOS CON METALES

\begin{tabular}{|c|c|c|c|c|c|}
\hline & \multicolumn{5}{|c|}{ Sector } \\
\hline & $1^{*}$ & $2 *$ & $3^{*}$ & $\mathrm{X}$ & Control \\
\hline $\begin{array}{c}\text { COT } \\
(\mathrm{g} \mathrm{C} / 100 \mathrm{~g})\end{array}$ & $\begin{array}{c}\mathbf{0 . 3 1}( \pm \mathbf{0 . 0 8}) \\
{[0.23-0.42]}\end{array}$ & $\begin{array}{c}\mathbf{0 . 4 0}( \pm \mathbf{0 . 3 6}) \\
{[0.16-0.88]}\end{array}$ & $\begin{array}{c}\mathbf{0 . 6 0}( \pm \mathbf{0 . 2 9}) \\
{[0.31-0.98]}\end{array}$ & $\begin{array}{c}0.44 \\
-\end{array}$ & $\begin{array}{c}\mathbf{1 . 4 2}( \pm \mathbf{0 . 0 1}) \\
{[1.41-1.44]}\end{array}$ \\
\hline $\begin{array}{c}\mathrm{AU} \\
(\mu \mathrm{g} \mathrm{N} / \mathrm{g} \times \mathrm{h})\end{array}$ & $\begin{array}{c}4.33( \pm 1.25) \\
{[3.08-5.52]}\end{array}$ & $\begin{array}{c}\mathbf{6 . 0 3}( \pm \mathbf{3 . 4 0 )} \\
{[1.51-9.01]}\end{array}$ & $\begin{array}{c}\mathbf{4 . 3 4}( \pm \mathbf{1 . 3 6}) \\
{[3.28-6.41]}\end{array}$ & $\begin{array}{c}4.90 \\
-\end{array}$ & $\begin{array}{l}\mathbf{1 0 . 5 7}( \pm \mathbf{0 . 3 4}) \\
{[10.20-10.86]}\end{array}$ \\
\hline $\begin{array}{c}\mathrm{RB} \\
(\mathrm{mg} \mathrm{CO} / \mathrm{kg} \times \mathrm{h})\end{array}$ & $\begin{array}{l}\mathbf{9 . 3 4}( \pm \mathbf{0 . 8 1}) \\
{[8.43-10.48]}\end{array}$ & $\begin{array}{c}\mathbf{8 . 0 3}( \pm \mathbf{1 . 2 7}) \\
{[6.29-8.97]}\end{array}$ & $\begin{array}{c}7.31( \pm \mathbf{0 . 6 1}) \\
{[6.54-8.07]}\end{array}$ & $\begin{array}{c}8.23 \\
-\end{array}$ & $\begin{array}{c}9.91( \pm \mathbf{0 . 0 2}) \\
{[9.90-9.93]}\end{array}$ \\
\hline $\begin{array}{c}\mathrm{BM} \\
(\mathrm{mg} \mathrm{C} / 100 \mathrm{~g})\end{array}$ & $\begin{array}{c}\mathbf{1 3 . 0 4}( \pm \mathbf{5 . 2 5}) \\
{[2.86-18.39]}\end{array}$ & $\begin{array}{l}\mathbf{9 . 7 5}( \pm \mathbf{8 . 1 5}) \\
{[0.33-22.84]}\end{array}$ & $\begin{array}{c}\mathbf{1 3 . 4 8}( \pm \mathbf{7 . 0 5}) \\
{[6.14-28.48]}\end{array}$ & $\begin{array}{c}12.09 \\
-\end{array}$ & $\begin{array}{l}\mathbf{2 2 . 7 9}( \pm \mathbf{5 . 6 8}) \\
{[17.09-28.46]}\end{array}$ \\
\hline
\end{tabular}

Se presentan los valores promedios (con su desviación estándar) obtenidos para los sectores 1, 2 y 3 del terreno impactado con metales y el suelo testigo, así como los valores máximos y mínimos de cada análisis

*Promedio de nueve determinaciones, COT: contenido de carbono orgánico, AU: actividad ureásica, RB: respiración basal, BM: biomasa microbiana, X: promedio de los tres sectores. 
situación. Aunque la RB no sufrió una afectación significativa, debe considerarse que al disminuir la $\mathrm{BM}$ en un $47 \%$ en las muestras impactadas con metales, la actividad respiratoria de la microbiota debería incrementarse.

En efecto, el cociente RB/BM en estas muestras fue de $0.68(8.226 / 12.087)$ y en el testigo de 0.43 (9.910/22.789), lo cual indica que la actividad respiratoria de la biomasa en muestras que contenían metales a concentraciones permisibles fue 1.58 $(0.68 / 0.43)$ veces mayor respecto al sistema testigo, lo cual demuestra la presencia de una condición de estrés microbiano.

Adicionalmente, los cocientes COT/BM en muestras impactadas y testigo fueron de 0.036 $(0.436 / 12.087)$ y $0.062(1.420 / 22.789)$, respectivamente, lo cual indica que la microbiota en el testigo dispone de 1.7 veces $(0.062 / 0.036)$ más material carbonado que las muestras impactadas. Esta situación confirma la disminución del COT en las muestras que contienen metales y una RB aparentemente normal en ambas muestras.

En la literatura se ha reportado el establecimiento de situaciones que alteran las poblaciones bacterianas en suelos contaminados por metales y produce estrés oxidativo (Fontanetti et al. 2011, Lemire et al. 2013, Sulmon et al. 2015). Dicho estrés implica un incremento en la síntesis de enzimas antioxidantes (óxido dismutasas, catalasas, peroxidasas, glutatión peroxidasas), proteínas queladoras de metales, metalotioninas, (Bozo et al. 2007, Sulmon et al. 2015) y sideróforos (Lemire et al. 2013).

Tales estrategias de emergencia requieren de fuentes energéticas para reponer el estado homeostático de la célula (Sulmon et al. 2015). En consecuencia, la energía proviene de la oxidación de moléculas carbonadas presentes en el hábitat donde proliferan los organismos, en este caso particular del suelo.

Los resultados correspondientes a la CB se muestran en el cuadro II. Se observó, para las muestras de ambas estaciones (lluviosa y de sequía) un incremento de la densidad bacteriana (UFC/g) a medida que el sector analizado se aleja de la planta de producción. Este incremento, podría indicar una menor concentración de metales en zonas más retiradas del punto de impacto de la actividad metalúrgica. Una situación similar se reportó al detectarse disminuciones en las concentraciones de $\mathrm{Zn}, \mathrm{Al}, \mathrm{Pb}$ y $\mathrm{Cd}$, en líquenes, conforme las muestras se alejaban de una carretera por donde se transportaba el mineral proveniente de una mina (Holt y Miller 2010).

Para la estación lluviosa los valores de $\mathrm{CB}$ se incrementaron desde $1.22 \times 10^{5}$ hasta $9.94 \times 10^{5} \mathrm{UFC} / \mathrm{g}$ en las secciones 1 y 3 , respectivamente. El testigo mostró valores de $39.8 \times 10^{5} \mathrm{UFC} / \mathrm{g}$. El promedio en las secciones impactadas fue de $6.65 \times 10^{5} \mathrm{UFC} / \mathrm{g}$ que, al compararse con el testigo, indicaron un $83 \%$ de disminución de la carga bacteriana.

En el caso de la estación seca, el promedio de CB en las secciones impactadas fue de $1.73 \times 10^{5} \mathrm{UFC} / \mathrm{g}$, con una variación de 0.63 a $4.08 \times 10^{5} \mathrm{UFC} / \mathrm{g}$, en tanto que el valor del testigo fue de $2.51 \times 10^{5} \mathrm{UFC} / \mathrm{g}$ y la disminución se calculó en $30 \%$.

Los resultados de la CB en ambas estaciones se correlacionan bien con la disminución referida de la $\mathrm{BM}$ en los sectores impactados. La diferencia en los valores de las muestras testigo se debe a la disponibilidad de agua, la cual es fundamental para la

CUADRO II. VARIACIÓN DE LA CARGA BACTERIANA CON LA ÉPOCA DEL AÑO EN MUESTRAS DE SUELO IMPACTADOS Y NO IMPACTADOS CON METALES

\begin{tabular}{lccccc}
\hline \multicolumn{5}{c}{ Carga bacteriana $\left(\mathrm{UFC} / \mathrm{g}\right.$ suelo) $\times 10^{-5}$} \\
\hline \multirow{2}{*}{ Época del año } & $1^{*}$ & $2^{*}$ & $3^{*}$ & $\mathrm{X}$ & Testigo \\
\cline { 2 - 6 } & $\mathbf{1 . 2 2}( \pm \mathbf{1 . 6 7})$ & $\mathbf{8 . 8 1}( \pm \mathbf{9 . 6 7 )}$ & $\mathbf{9 . 9 4}( \pm \mathbf{5 . 9 3 )}$ & $\mathbf{6 . 6 5}$ & $\mathbf{3 9 . 8}$ \\
\hline Lluviosa & {$[0.32-3.16]$} & {$[2.51-19.95]$} & {$[3.98-15.84]$} & - & - \\
\hline Sequía & $\mathbf{0 . 6 3 ( \pm \mathbf { 0 . 8 2 } )}$ & $\mathbf{0 . 4 8}( \pm \mathbf{0 . 1 6})$ & $\mathbf{4 . 0 8}( \pm \mathbf{1 . 3 0})$ & $\mathbf{1 . 7 3}$ & $\mathbf{2 . 5 1}$ \\
& {$[0.16-1.58]$} & {$[0.31-0.63]$} & {$[3.16-5.01]$} & - & - \\
\hline
\end{tabular}

Se presentan los valores promedios obtenidos (con su desviación estándar) para los sectores 1,2 y 3 del terreno impactado con metales y el suelo testigo, así como los valores máximos y mínimos de la carga bacteriana en ambas épocas del año

*Promedio de nueve determinaciones, UFC: unidades formadoras de colonias, X: promedio de los sectores 1,2 y 3 
proliferación bacteriana. En general, la CB en la estación lluviosa siempre fue mayor en todos los sectores al compararse con los valores de la estación seca.

Si bien en la estación lluviosa se obtuvieron los valores más altos de $\mathrm{CB}$, es contrastante que la mayor reducción en este parámetro se detectó en esta época. Esto puede deberse a una mayor disponibilidad de los metales para la población bacteriana, debida a la solubilización inducida por los niveles de agua relativamente altos presentes en el terreno, lo cual está restringido en terrenos más secos.

Como era de esperarse, hubo variabilidad en la morfología macroscópica de las colonias bacterianas aisladas de las muestras de suelo contaminado y cultivadas en AR, las cuales se diferenciaron con base en su forma, elevación, borde, tamaño y color (resultados no mostrados). Sin embargo, luego de una minuciosa observación sólo se lograron detectar 12 morfotipos bacterianos diferentes, que se denominaron cepas MT1 a la MT12.

Es notorio el bajo nivel de diversidad biológica en las muestras de suelo, lo cual ha sido reportado por otros investigadores (Smets et al. 2003, Bozo et al. 2007).

Aunque se ha reportado que sólo 0.1 a $1 \%$ de la población microbiana puede detectarse en muestras ambientales mediante técnicas clásicas de cultivo in vitro (Malik et al. 2008), actualmente se efectúan intentos para mejorar estos porcentajes de detección (Tanaka 2014). No obstante, se ha sugerido que la carga bacteriana podría superar el billón de organismos por gramo de suelo pertenecientes a más de mil diferentes especies (Torsvik y Ǿvreas 2002).

Como es sabido, en la actualidad existen técnicas moleculares (mediante la identificación del gen ARNr16S) y bioquímicas (perfil de ácidos grasos metil esterificados, entre otras) que permiten evaluar la diversidad de microorganismos cultivables y no cultivables de una manera más exhaustiva (Malik et al. 2008). Sin embargo, este trabajo sólo pretende mostrar los cambios en la diversidad de las bacterias cultivables, asociados con la presencia de metales en concentraciones que se estiman permisibles según la legislación venezolana.

Con base en la capacidad proliferativa de las 12 cepas aisladas, y por consideraciones logísticas, sólo cinco de ellas se sometieron a los protocolos de identificación a nivel de género: las cepas MT1, MT4, MT5, MT6 y MT11. En el cuadro III se indican los resultados de las pruebas bioquímicas, observaciones al microscopio de luz y su identificación taxonómica. Se asignaron las denominaciones MT1 al género Rhotia, MT4 a Vibrio, MT5 a Klebsiella, MT6 a Acinetobacter y MT11 a Raoultella.
La identificación de los géneros bacterianos se efectuó luego del análisis de las 23 pruebas (bioquímicas, fisiológicas y morfológicas) realizadas y tomando como referencia publicaciones especializadas en la identificación bacteriana (Forbes et al. 2004, Win et al. 2008). Es claro que no se indican especies, pero la asignación de géneros es totalmente válida.

Las cinco cepas bacterianas caracterizadas fueron sometidas a análisis de sensibilidad en medios AR con contenido de metales mediante la técnica de difusión en placa (Abskharon et al. 2008). Un halo de inhibición menor a $20 \mathrm{~mm}$ se consideró como capacidad de resistencia al metal (Schmidt y Schlegel 1989).

Todas las cepas fueron sensibles a cobalto (halos de inhibición superiores a $20 \mathrm{~mm}$ ) y el sodio no ejerció efectos negativos sobre ellas (se incluyó como testigo de la prueba). Todas las cepas mostraron resistencia al $\mathrm{Ni}^{2+}, \mathrm{Cr}^{3+}$ y $\mathrm{Cr}^{6+}$; al respecto, el níquel y el cromo, junto con el cobre y cadmio, son los metales más comúnmente reportados como contaminantes del medio ambiente (Alboghobeish et al. 2014).

La inspección de los halos de inhibición indicó variabilidad en la resistencia a los metales (Cuadro IV), siendo los correspondientes a la cepa MT6 los de menor diámetro (iguales o menores a $15 \mathrm{~mm}$ ), lo que indicó la más alta capacidad de resistencia en Acinetobacter sp. Consecuentemente, para la ejecución del diseño experimental factorial $3^{3}$ se empleó Acinetobacter. Los datos obtenidos se presentan como gráficas de superficies de respuesta a $\mathrm{Ni}^{2+}, \mathrm{Cr}^{3+}$ y $\mathrm{Cr}^{6+}$ en la figura 1.

La disminución de la densidad óptica (DO) - medida de proliferación de la población bacterianaes evidente al incrementar la concentración del metal, alcanzándose los niveles más bajos y con poca variabilidad en concentraciones superiores a $5.0 \mathrm{mM}$. Resultados similares se obtuvieron al variar el $\mathrm{pH}$ del medio de 9.0 a 6.0 .

Al comparar las variaciones de la DO detectadas con la variación de la concentración del metal y la de $\mathrm{pH}$, se puede concluir que la concentración de metal es el factor preponderante en la capacidad proliferativa de la cepa bacteriana, ya que las mayores variaciones en la DO se obtuvieron al variar la concentración del metal.

El análisis de varianza indicó que la concentración de metal y el pH, más la interacción de ambos parámetros, tuvieron una influencia significativa en el crecimiento bacteriano, al establecer un valor de $\mathrm{p}$ crítico $<0.05$. Esto se corroboró mediante un diagrama de Pareto en que los parámetros ya 
CUADRO III. CARACTERÍSTICAS BIOQUÍMICAS Y MORFOLÓGICAS DE LAS CEPAS BACTERIANAS AISLADAS

\begin{tabular}{lccccc}
\hline Característica & MT1 & MT4 & MT5 & MT6 & MT11 \\
\hline Género & Rothia & Vibrio & Klebsiella & Acinetobacter & Raoultella \\
\hline Forma & CB & B & B & B & B \\
Gram & + & - & - & - & - \\
Esporas & - & - & - & - & - \\
Glucosa (O/F) & O/F & F & F & O/F & F \\
Lactosa & - & - & + & + & - \\
Catalasa & + & + & + & + & + \\
Motilidad & - & + & - & - & - \\
Ácido sulfhídrico & - & - & - & - & - \\
Indol & - & - & - & - & - \\
Citrato & + & + & + & - & + \\
Gas & + & - & - & - & - \\
KIA & $\mathrm{K} / \mathrm{A}$ & $\mathrm{K} / \mathrm{K}$ & $\mathrm{K} / \mathrm{A}$ & $\mathrm{K} / \mathrm{A}$ & $\mathrm{K} / \mathrm{A}$ \\
Nitratos & + & + & + & + & + \\
Ureasa & - & - & - & - & - \\
Lisina & - & + & - & - & + \\
Almidón & - & - & - & - & - \\
Rojo de metilo & + & + & + & + & - \\
Voges-Proskauer & + & - & - & - & + \\
Agar Mac Conkey & + & + & + & + & + \\
Agar cetrimida & + & - & - & - & + \\
Agar SS & + & + & - & - & - \\
Agar manitol salado & - & - & - & - & - \\
\hline & & & & &
\end{tabular}

${ }^{\mathrm{d}}$ Respuesta débil

+: reacción positiva, -: reacción negativa, B: bacilo, CB: cocobacilo, O: oxidación, F: fermentación, A: respuesta ácida, K: respuesta alcalina, KIA: agar con hierro de Kligler

CUADRO IV. PRUEBA DE SENSIBILDAD A DIVERSOS METALES $(100 \mu \mathrm{M})$ EN CEPAS AISLADAS DE SUELOS CONTAMINADOS

\begin{tabular}{lccccc}
\hline Cepa bacteriana & \multicolumn{5}{c}{ Diámetro del halo de inhibición (mm) } \\
\cline { 2 - 6 } & $\mathrm{Co}^{+2}$ & $\mathrm{Ni}^{+2}$ & $\mathrm{Cr}^{+3}$ & $\mathrm{Cr}^{6+}$ & $\mathrm{Na}^{+}$ \\
\hline Rothia sp. & 28.0 & 0.0 & 13.0 & 15.0 & 0.0 \\
Vibrio sp. & 26.0 & 0.0 & 14.0 & 10.5 & 0.0 \\
Klebsiella sp. & 25.0 & 12.0 & 14.0 & 13.0 & 0.0 \\
Acinetobacter $\mathrm{sp}$. & 25.0 & 0.0 & 13.0 & 10.5 & 0.0 \\
Raoultella sp. & 26.0 & 10.0 & 14.5 & 15.0 & 0.0 \\
\hline
\end{tabular}

mencionados presentaron valores críticos de $\mathrm{p}>2.0$ (datos no mostrados).

Es importante señalar que a $\mathrm{pH}$ superiores a 6-7 la disponibilidad del $\mathrm{Cr}^{3+} \mathrm{y} \mathrm{Ni}^{2+}$ disminuye considerablemente debido a la formación de sus respectivos hidróxidos insolubles, lo que reduce la concentración activa de estos metales en las condiciones experimentales usadas en las determinaciones.

Una limitación de nuestros datos es que no se han tomado en consideración aspectos físicos y químicos del suelo que podrían influir en la biodisponibilidad de los metales, tales como capacidad intercambiadora de cationes, aniones quelantes de metales y fuerza iónica del suelo (Lemire et al. 2013).

Adicionalmente, las gráficas de superficie de respuesta (Fig. 1) pueden sugerir que las concentraciones mínimas de los metales ensayados a las que se inhibió la capacidad de duplicación de los cultivos bacterianos (variación de absorbancia cero) estarían ubicadas en el intervalo de 5-7 mM. Datos de otros laboratorios reportan valores de concentraciones mínimas inhibitorias de 3-5 mM Ni (Bhadra et al. 2006) y 3-4 mM Cr (Essahale et al. 2012) para diferentes cepas de Acinetobacter. Valores de 2.7, $3.4,13.6$ y $54.5 \mathrm{mM}$ para Ni y $1.9,3.8$ y $7.7 \mathrm{mM}$ para $\mathrm{Cr}$ han sido reportados para diferentes cepas de los géneros Pseudomonas y Alcaligenes (Moraga et al. 2003).

Respecto de los cinco géneros bacterianos identificados en este estudio, otros autores han reportado previamente resistencia a metales y la dependencia de ésta a la presencia de plásmidos para Vibrio (Zhang et 

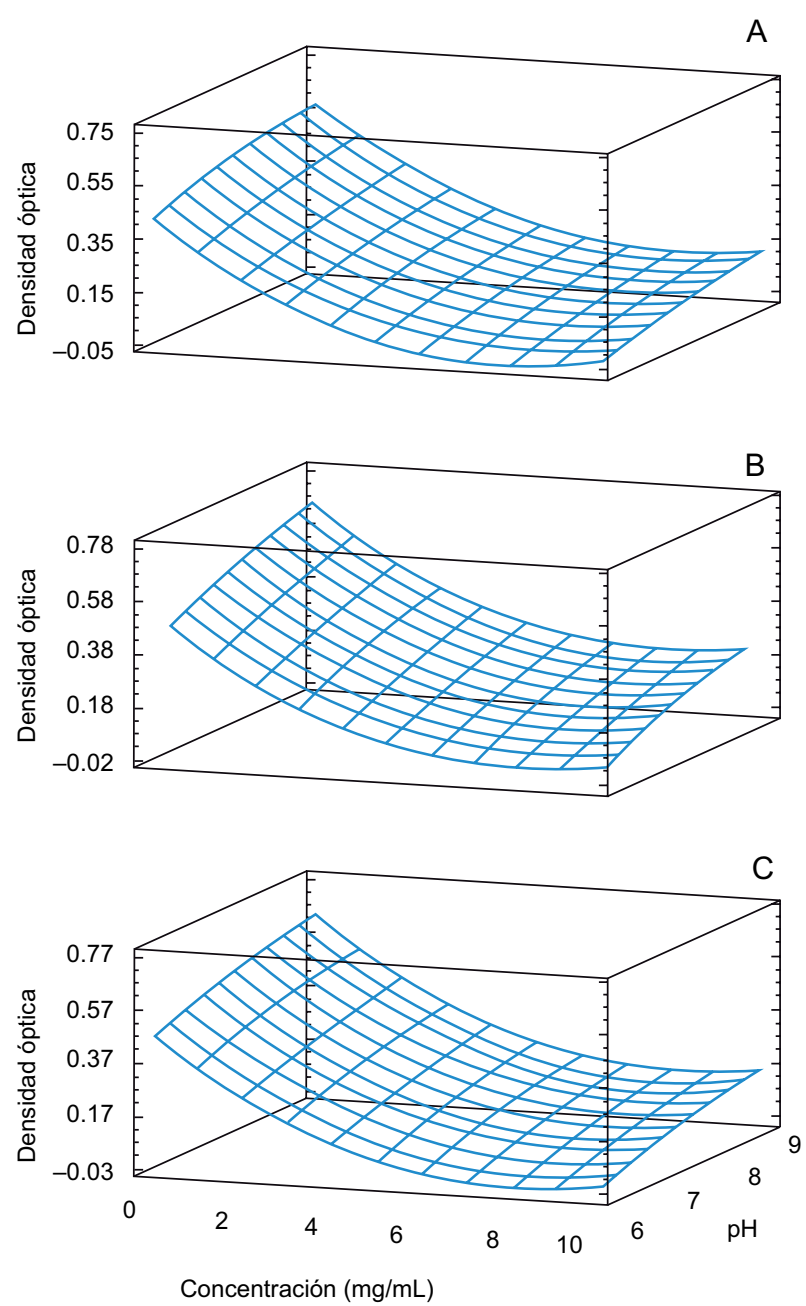

Fig. 1. Superficie de respuesta para el crecimiento bacteriano en función del $\mathrm{pH}$ y la concentración de: (a) $\mathrm{Ni}^{+2}$, (b) $\mathrm{Cr}^{+3}$ y (c) $\mathrm{Cr}^{+6}$

al. 2012), Klebsiella (Matasaje et al. 2011), Acinetobacter (Essahale et al. 2012) y Raoultella (Sun et al. 2015). No obstante, la dualidad resistencia a metales/ plásmido no siempre se cumple. En un caso reportado para $\mathrm{Pb}$ la resistencia al metal fue asignada a genes cromosomales, aun determinándose resistencia a otros metales en plásmidos contenidos en la misma cepa bacteriana (Aktan et al. 2013).

Es importante señalar la baja diversidad bacteriana detectada en el suelo analizado. De acuerdo con los artículos 49 y 50 del decreto 2635 de la legislación venezolana, que establece valores permisibles para residuos sólidos empleando prácticas de confinamiento en suelos, los niveles máximos de cromo total son de $500 \mathrm{mg} / \mathrm{kg}$, en tanto que para lixiviados se establecen $5 \mathrm{mg} / \mathrm{L}$ para $\mathrm{Cr}^{+6} \mathrm{y} \mathrm{Ni}^{+2}$ (anexo D de dicho decreto), equivalentes a 96 y $85 \mu \mathrm{M}$, respectivamente (Gaceta Oficial 1998).

Evaluacionesrealizadas por nuestro grupo han determinado que los niveles disponibles de estos dos metales en el suelo estudiado $\left(\left[\mathrm{Cr}^{+6}\right]=1.73\right.$ $\mathrm{mg} / \mathrm{kg},\left[\mathrm{Ni}^{+2}\right]=1.25 \mathrm{mg} / \mathrm{kg}$ ) no superan los niveles establecidos por la normativa ambiental, lo cual indicarían que los suelos no están contaminados (Sánchez 2012). No obstante, la evaluación de los parámetros bioquímicos determinados en este estudio (COT, AU y BM) arrojó valores estadística y significativamente disminuidos, al compararse con los obtenidos en el área control. Adicionalmente, la biodiversidad y carga bacterianas estuvieron seriamente disminuidas.

Es relevante mencionar que se ha reportado en la literatura que bajas concentraciones, consideradas no perjudiciales, de sustancias tóxicas pueden ejercer efectos estimulatorios beneficiosos en organismos de diferentes taxa, desde bacterias a plantas y metazoos (Costantini et al. 2010, Sulmon et al. 2015), fenómeno denominado hormesis.

De hecho, las cepas bacterianas aisladas constituyen una subpoblación aclimatada a bajas concentraciones de metales, aunque la mayor parte de la microbiota se redujo drásticamente en términos de especies y carga bacteriana. Debido a esta situación, los efectos de tales concentraciones de metales y cambios en la microbiota sobre la capacidad de dichos suelos para sustentar labores agropecuarias - es decir, sobre la salud del suelo - resultan impredecibles.

En concordancia con estos resultados, la macrobiota vegetal en la parcela impactada es casi inexistente, si se le compara con la parcela testigo, y el aspecto general de la tierra (color, textura, granulosidad) también muestra diferencias.

Parece pertinente que los niveles permisibles de metales en suelos deberían evaluarse nuevamente, ya que la evidencia experimental presentada en este trabajo es indicativa de que, aun con niveles de metales "relativamente bajos", las propiedades biológicas y bioquímicas del suelo se alteraron negativamente. Por tanto, la biodiversidad y biomasa bacterianas deberían considerarse e incluirse en la legislación como bioindicadores de contaminación en suelos. Esto redundará en una mejor calidad de vida para la sociedad y en el aseguramiento de la sustentabilidad de los ambientes naturales.

Estudios de esta naturaleza constituyen voces de alerta que deberían tomar en cuenta los entes oficiales encargados de garantizar las condiciones físicas, químicas, bioquímicas y biológicas de los ecosistemas. 


\section{CONCLUSIONES}

Los parámetros bioquímicos (porcentaje de COT, AU y BM) no disminuyeron estadísticamente y la RB no se afectó estadísticamente. Sin embargo, el cociente RB/BM fue elevado respecto al suelo testigo, lo cual indica empobrecimiento del material orgánico en el suelo impactado con metales y como resultado afectación de la salud del suelo.

La diversidad y carga bacterianas medidos en los suelos fueron bajos, con valores de $\mathrm{pH} 9.0$ y concentraciones de metales consideradas como permisibles por la legislación venezolana vigente.

Se aislaron únicamente 12 morfotipos diferentes y se asignaron cinco de ellos a los géneros Rhotia, Vibrio, Klebsiella, Acinetobacter y Raoultella. La carga bacteriana disminuyó en 80 y $30 \%$ en las estaciones lluviosa y de sequía, respectivamente, al compararse con el suelo testigo.

Estos datos experimentales permiten aseverar que bajas concentraciones de metales, aun consideradas permisibles, alteran negativamente la calidad de los suelos.

\section{REFERENCIAS}

Abskharon R.N.N., Hassan S.H.A., Gad El-Rab S.M.F. y Shoreit A.A.M. (2008). Heavy metal resistance of E. coli isolated from wastewater sites in Assiut City, Egypt. Environ. Contam. Toxicol. 81 (3), 309-315. DOI: $10.1007 / \mathrm{s} 00128-008-9494-6$

Aktan Y., Tan S. y Icgen B. (2013). Characterization of lead resistant river isolate Enterococcus faecalis and assessment of its multimetal and antibiotic resistance. Environ. Minit. Assess. 185 (6), 5285-5293.

DOI: $10.1007 / \mathrm{s} 10661-012-2945-\mathrm{x}$

Alboghobeish H., Tahmourespour A. y Doudi M. (2014). The study of nickel resistant bacteria (NiRB) isolated from wastewaters polluted with different industrial sources. J. Environ. Health Sci. Eng. 12, 44.

DOI: $10.1186 / 2052-336 \mathrm{X}-12-44$

Anderson J.P. y Domsch K.H. (1978). A physiological method for the quantitative measurement of microbial biomass in soil. Soil Biol. Biochem. 10 (3), 215-221. DOI: 10.1016/0038-0717(78)90099-8

Anderson J.P. (1982). Soil respiration. En: Methods of soil analysis. Part 2. Chemical and microbiological properties. 2a ed. Soil Science Society of America, núm. 9, Winsconsin, EUA, pp 831-871.

Bhadra B., Nanda A.K. y Chakraborty R. (2006). Inducible nickel resistance in a river isolate of India phylogenetically ascertained as a novel strain of Acinetobacter junii. World J. Microbiol. Biotechnol. 22 (3), 225-232. DOI: $10.1007 / \mathrm{s} 11274-005-9026-\mathrm{z}$

Black J.G. (2012). Microbiology. Principles and explotations. 8a ed. Jhon Wiley and Sons, Arlington, Virginia, EUA, 975 pp.

Bozo L., Fernández M., López M., Reyes R. y Suárez P. (2007). Biomarcadores de contaminación química en comunidades bacterianas. Interciencia 32 (1), 8-13. DOI: 0378-1844/07/01/008-06

Cortez J., Ruiz Y., Medina L. y Valbuena O. (2013). Efecto de medios de cultivo preparados con agua de mar sobre indicadores sanitarios en aguas marinas de balnearios en Chichiriviche, estado Falcón, Venezuela. Rev. Soc. Ven. Microbiol. 33 (2), 122-128.

Costantini D., Metcalfe N.B. y Monaghan P. (2010). Ecological processes in a hormetic framework. Ecol. Lett. $13(11), 1435-1447$.

DOI: 10.1111/j.1461-0248.2010.01531.X.

Couter A. (2003). Plasmid DNA supercoiling and survival in long-term cultures of Escherichia coli: Role of $\mathrm{NaCl}$. J. Bacteriol. 185 (1), 5324-5327.

DOI: $10.1128 / J B .185 .17 .5324-5327.2003$

Darcan C., Ozkanga R., Idil O. y Fint K.P. (2009). Viable but non-culturable state of Escherichia coli related to EnvZ under the effect of $\mathrm{pH}$, starvation and osmotic stress in seawater. Pol. J. Microbiol. 58 (4), 307-317.

Dell'Amico E., Mazzochi M., Cavalca L., Allievi L. y Andreoni V. (2008). Assessment of bacterial community structure in a long-term cooper-polluted ex-vineyard soil. Microbial. Res. 163 (6), 671-683.

DOI: $10.1016 /$ j.micres.2006.09.003

Essahale A., Malki M., Marin I. y Moummi M. (2012). Hexavalent chromium reduction and accumulation by Acinetobacter $\mathrm{AB} 1$ isolated from Fez Tanneries in Morocco. Indian J. Microbiol. 52 (1), 48-53.

DOI: $10.1007 / \mathrm{s} 12088-011-0187-1$

Fontanetti C.S., Nogarol L.R., Souza R.B., Pérez D.G. y Maziviero G.T. (2011). Bioindicators and biomarkers in the assessment of soil toxicity. En: Soil contamination (Pascucci S., Ed.). InTech Rijeka, Croacia, pp. 143-168. DOI: $10.5772 / 25042$

Forbes B.A., Sahm D.F. y Weissfeld A.S. (2004). Bailey y Scott. Diagnóstico microbiológico. 11a ed. Editorial Médica Panamericana, Buenos Aires, Argentina, $1136 \mathrm{pp}$.

Gaceta Oficial (1998). Decreto 2635. Normas para el control de la recuperación de materiales peligrosos y el manejo de los desechos peligrosos. Reforma parcial del Decreto 2289. República Bolivariana de Venezuela. Gaceta Oficial Extraordinaria núm. 5245, 3 de agosto.

Gadd G.M. (2010). Metals, minerals and microbes: Geomicrobiology and bioremediation. Microbiology 156 (3), 609-643. DOI: 10.1099/mic.0.037143-0 
Holt E.A. y Miller S.W. (2010). Bioindicators: Using organisms to measure environmental impacts. Nature Educational Knowledge 3 (10), 8.

Kandeler E. y Gerber H. (1988) Short-term assay of urease activity using colorimetric determination of ammonium. Biol. Fertil. Soils 6 (1), 68-72.

DOI: $10.1007 / \mathrm{BF} 00257924$

Lemire J., Harrison J. y Turner R. (2013). Antimicrobial activity of metals: Mechanisms, molecular targets and applications. Nat. Rev. Microbiol. 11 (6), 371-384. DOI: 10.1038/nrmicro3028

Malik S., Beer M., Meghara M. y Naidu R. (2008). The use of molecular techniques to characterize the microbial communities in contaminated soil and water. Environ. Int. 34 (2), 265-276.

DOI: $10.1016 /$ j.envint.2007.09.001

Matasaje L.F., Boyd D.A., Willey B.M., Prayitno N., Kreiswirth N., Gelosia A., Poutanen S.M., Low D.E., Jenkins S.G., Katz K. y Mulvey M.R. (2011). Plasmid comparison and molecular analysis of Klebsiella pneumoniae harbouring blaKPC from New York city and Toronto. J. Antimicrob. Chemoth. 66 (6), 1273-1277. DOI: $10.1093 / \mathrm{jac} / \mathrm{dkr} 092$

McDougald D., Weichart D., Rice S., Gerets J. y Kjelleberg S. (1998). Nonculturability: Adaptation or debilitation. FEMS Microbiol. Ecol. 25 (1), 1-9.

DOI: 10.1111/j.1574-6941.1998.tb00455.x

Moraga R., Merino C. y Mondaca M.A. (2003). Resistencia a metales pesados en bacterias aisladas de la bahía de Iquique. Investig. Mar. 31 (1), 91-95. DOI: $10.4067 / \mathrm{S} 0717-71782003000100010$

Piotrowska-Seget Z., Cycon M. y Kozdrój J. (2005). Metal-tolerant bacteria occurring in heavily polluted soil and mine spoil. Appl. Soil Ecol. 28 (3), 237-246. DOI: 10.1016/j.apsoil.2004.08.001

Sánchez C. (2012). Evaluación toxicológica de suelos impactados por la actividad metalúrgica en TinaquilloEdo. Cojedes. Tesis de Licenciatura. Departamento de Química, Facultad Experimental de Ciencias y Tecnología, Universidad de Carabobo, Valencia, Venezuela, $106 \mathrm{pp}$.

Schmidt T. y Schlegel H.G. (1989). Nickel and cobalt resistance of various bacteria isolated from soil and highly polluted domestic and industrial wastes. FEMS Microbiol. Ecol. 5 (5), 315-328. DOI: $10.1111 / \mathrm{j} .1574-6968.1989 . t b 03386 . x$
Silver S. y Phung L.T. (2005). A bacteria view of the periodic table: genes and proteins for toxic inorganic ions. J. Ind. Microbiol. Biotechnol. 32 (11-12), 578-605. DOI: $10.1007 / \mathrm{s} 10295-005-0019-6$

Smets B.F., Morrow J.B. y Arango-Pinedo C. (2003). Plasmid introduction in metal-stressed subsurface-derived microcosms: plasmid fate and community response. Appl. Environ. Microbiol. 69 (7), 4087-4097.

DOI: 10.1128/AEM.69.7.4087-4097.2003

Sulmon C., Baaren J., Cabello-Hurtado F., Gouesbet G., Hennion F., Mony C., Renault D., Bormans M., El Amrani A., Wiegand C. y Gérard C. (2015). Abiotic stressors and stress responses: What commonalities appear between species across biological organization levels? Environ. Pollut. 1987, 66-77. DOI: 10.1016/j.envpol.2015.03.013

Sun F., Yin Z., Feng J., Qiu Y., Zhan D., Lou W., Yang H., Yang W., Wang J., Chen W., Xia P. y Zhou D. (2015). Production of plasmid-encoding NDM-1 in ). High incidence of plasmids in marine VibrioXia, P; Zhou, D. (2015). Fronteirsand Toroclinical Raoultella ornithinolytica and Leclercia decarboxylata from China. Front. Microbiol. 6, 458. DOI: 10.3389/fmicb.2015.00458

Tanaka T. (2014). A hidden pitfall in the preparation of agar media undermines microorganism cultivability. Appl. Environ. Microbiol. 80 (24), 7659-7666.

DOI: 10.1128/AEM.02741-14

Torsvik V. y Ǿvreas L. (2002). Microbial diversity and function in soil: from genes to ecosystems. Curr. Opin. Microbiol. 5 (3), 240-245. DOI: $10.1016 /$ S1369-5274(02)00324-7

Wallinga I., Kithome M., Novozamsky I., Houba V.J.G. y Van der Lee J.J. (1992). Spectrophotometric determination of organic carbon in soil. Commun. Soil Sci. Plant Anal. 23 (16-16), 1935-1944.

DOI: $10.1080 / 00103629209368715$

Win W.C., Allen S.D., Janda W.M., Koneman E.W., Procop G.W., Schreckenberger P.C. y Woods G.L. (2008). Koneman. Diagnóstico microbiológico: texto y atlas en color. 6a ed. Editorial Médica Panamericana. Buenos Aires, Argentina, 1475 pp.

Zhang K., Pan L., Zhao Z. y Gu J.D. (2012). High incidence of plasmids in marine Vibrio species isolate from Mai Nature Reserve of Hong Kong. Ecotoxicology 21 (6), 1661-1666.

DOI: $10.1007 / \mathrm{s} 10646-012-0939-7$ 